\title{
Biyobenzer ilaçların preklinik ve klinik performanslarının değerlendirilmesi
}

\section{Evaluation of preclinical and clinical performance of biosimilar drugs}

Turgut Emrah Bozkurt॰

Hacettepe Üniversitesi, Eczacılık Fakültesi, Farmakoloji Anabilim Dalı, Ankara, Türkiye

Öz

Biyoteknolojik ilaçlar doku veya hücre kültürleri gibi canlı organizmalar aracılığıyla genellikle rekombinant DNA teknolojisi kullanılarak üretilen kompleks, büyük moleküllerdir. Biyobenzerler daha önce onaylanmış olan referans biyolojik ilaçlara yüksek oranda benzeyen biyolojik ilaçlardır. Biyobenzer ilaçların referans ilaca kalite, etkililik ve güvenlilik açısından benzerliğinin gösterilmesi küçük moleküllerle karşılaştırıldıklarında çok daha karmaşık bir süreçtir. Ulusal ve uluslararası kılavuzlar biyobenzerlerin performanslarının değerlendirilebilmesi için genel bir çerçeve oluşturmuşlardır. Ancak, biyoteknolojik ilaçların sayılarının fazlalığı ve etki mekanizmalarının çeşitliliği bu ürünlerin performanslarının değerlendirilmelerini karmaşık bir hale getirmektedir. Bu makalede biyobenzerlerin eşdeğerliğini değerlendirmek için önemli noktalar son gelişmeler ve ilgili kılavuzlar doğrultusunda sunulmuş ve tartışılmıştır.

Anahtar Sözcükler: Biyobenzer, ilaç, preklinik, klinik.

\begin{abstract}
Biotechnological drugs are complex, large molecules which are manufactured by living organisms such as tissue cultures or cells mostly using recombinant DNA technology. Biosimilars are biological medicines that are highly similar to their already approved biological reference medicines. To establish the similarity of a biosimilar to its reference drug in means of quality, efficacy and safety is a much more complicated procedure when compared to small molecules. International and national guidelines have created a general perspective for evaluating the performance of biosimilars. However, the large variety of biotechnological drugs and their wide range of action mechanisms make this evaluation process complicated. In this paper, the major issues for evaluating the similarity of biosimilars are reported and discussed according to the recent literature and guidelines.
\end{abstract}

Keywords: Biosimilar, drug, preclinical, clinical.

İlaç olarak kullanılacak yeni bir molekülün preklinik ve klinik tüm faz aşamalarını tamamlayarak pazara çıkması bilindiği üzere yaklaşık olarak on yıllık bir süre ve çeşitli verilere göre değişen 1-2,5 milyar dolarlık bir maliyet ile gerçekleşebilmektedir. Son yıllarda pazar payı giderek artan biyoteknolojik ilaçlar için de bu durum geçerli olmakla birlikte, konvansiyonel ürünlerle karşılaştırıldıklarında Ar-Ge maliyetleri daha yüksektir. Sağlık harcamaları açısından bakıldığında sosyal güvence sistemleri tarafından ilaçlara ödenen tutar oldukça önemli bir kalem olarak karşımıza çıkmaktadır. İlaç endüstrisi tarafından patent süresi bitmiş olan ilaçların eşdeğerlerinin üretilerek pazara sunulması ilaç fiyatlarında düşmeye sebep olarak geri ödeme sistemine önemli katkı sağlamaktadır. Bu durum üretim maliyetleri, dolayısıyla da fiyatları konvansiyonel ürünlere göre çok daha yüksek olan biyoteknolojik ürünler için de geçerlidir. Biyoteknolojik ürünlerin ilaç olarak geçmişi çok uzun olmadığından bu ürünlerin benzerlerinin pazara çıkması yaklaşık 12-13 sene gibi nispeten yakın bir zamanda başlamıştır. Ancak son beş yıla bakılacak olursa tüm dünyada bu ürünlerin benzerleri ile ilgili yoğun bir ruhsat trafiği görülmektedir. 
$\mathrm{Bu}$ durumun en önemli sebebi çok büyük pazar payı olan birçok biyoteknolojik molekülün patent sürelerinin bitmiş ya da bitmek üzere olmasıdır. Konvansiyonel ürünlerde kullanılan biyoeşdeğer terminolojisi biyoteknolojik ürünler için geçerli değildir. Çünkü moleküllerin çok büyük ve kompleks olması, tersiyer yapılarındaki ufak farklılıklar ve bunun gibi birçok fizikokimyasal özellik bire bir aynı olacak şekilde üretilmelerini zorlaştırmaktadır. Bu nedenle de bu ürünler için tüm dünyada "biyobenzer" terminolojisi kullanılmaktadır. Buradaki "benzer" terimi eşdeğer olarak üretilen ürünün orjinatör firma tarafından üretilen referans ürün ile benzer etkililik ve güvenlilik göstermesi durumunu anlatmak için kullanılmakta olup, bu benzerliğin derecesi bilimsel kılavuzlarla belirtilmektedir (1, 2). Konvansiyonel ürünler için biyoeşdeğerliğin ispatlanması ve eşdeğer ürünün pazara çıkması biyobenzer ürünlere göre çok daha kısa sürede ve çok daha az maliyetle olmaktadır.

Bugün biyobenzer olarak pazara çıkan moleküllere bakıldığında eritropoietin, granülositkoloni stimüle edici faktör (G-CSF), insülin, düşük molekül ağırıklı heparin (DMAH), somatotropin, interferonlar ve monoklonal antikorlar gibi ürünler görülmektedir. Günümüzde özellikle monoklonal antikorlar birçok farklı kullanım alanları olması nedeni ile oldukça fazla ilgi görmekte ve dolayısıyla bu grupta çok sayıda biyobenzer ürün pazara girmektedir. Diğer taraftan monoklonal antikorlar yukarıda saydığımız moleküller içerisinde yapıca en büyük, en karmaşık dolayısıyla da üretiminin en zor olduğu molekül grubunu oluşturmaktadırlar. Ancak dünyada en çok para harcanan biyoteknolojik ürünler listesi incelendiğinde bu listenin önemli bir kısmının ve özellikle üst sıraların bu moleküller tarafından işgal edildiği görülmektedir $(3,4)$.

Biyobenzer ürünlerin referans ürün ile benzerliğinin gösterilmesi için küçük moleküllerden farklı olarak çok detaylı bir kalite karşılaştırıması gerekmektedir. Bu süreç içerisinde fizikokimyasal karakterizasyon başta olmak üzere ürünün farmasötik kalitesi son teknoloji kullanılarak yapılan çalışmalarla gösterilmelidir. Bu süreç kendi içerisinde karmaşık, iş yoğun ve tecrübe gerektiren bir süreç olup, buradaki küçük farklılıklar ya da belirsizlikler sonraki süreçlerin tamamını olumsuz etkilemektedir. Kalite basamağının uygun şekilde tamamlanmasını takiben preklinik çalışmalara geçilmektedir. Burada hangi çalışmaların yapılacağına molekül, molekülün ait olduğu sınıf, endikasyon, endikasyon çeşitliliği, molekülün terapötik indeksi gibi parametreler dikkate alınarak karar verilir. Bununla ilgili olarak Avrupa İlaç Ajansı (EMEA), Amerikan Gıda ve İlaç Dairesi (FDA), Türkiye İlaç ve Tıbbi Cihaz Kurumu (TITCK) tarafından hazırlanmış olan kılavuzlar yapılması gereken çalışmalar ile ilgili genel çerçeveyi belirlemeye yönelik öneriler sunmaktadır. Bu konuda EMEA'da biyobenzer ürünler ile ilgili genel bir kılavuzun yanı sıra eritropoietin, G-CSF, insülin, somatotropin, interferonlar, DMAH ile ilgili spesifik kılavuzlar vardır (1,5-10). Günümüzde üzerinde en yoğun olarak çalışılmakta olan monoklonal antikorlar ile ilgili olarak da ayrı bir EMEA kılavuzu mevcuttur (11). Ancak monoklonal antikorlar sınıfındaki molekül sayısı ve etki mekanizmalarındaki çeşitlilik dikkate alındığında bu alandaki çalışmaların kılavuzda belirtilen ana çerçeve doğrultusunda ürün bazında güncel bilimsel literatür verilerine göre dizayn edilmesi gerekliliği ortadadır. Bu nedenle monoklonal antikorlar ile ilgili geliştirilme çalışmalarında benzerliğin gösterilmesi için seçilen preklinik ve klinik çalışmalarla ilgili gerekçelerin uygun şekilde rasyonalize edilmesi gerekir.

EMEA kılavuzlarında biyobenzerliğin gösterilebilmesi için in vitro farmako-toksikolojik çalışmaların tüm ürün grupları için gerekli olduğu belirtilmektedir. In vivo (deney hayvanları üzerinde) çalışmalar ise gerek görülmesi halinde yapılmalıdır. Burada mümkünse deney hayvanı kullanılmadan yeterli düzeyde bilimsel kanıt elde etmek önemlidir. Benzerliğin in vitro denemeler ile detaylı olarak ispatlanamadığı durumlarda in vivo çalışmalara başvurulmalıdır. Bu durumda da uygun şekilde gerekçelendirilerek, yapılan çalışmaların seçim nedenleri, güven aralıkları, sonuçların bilimsel literatür ile birlikte yorumlanması, yapılmayan çalışmalar varsa nedenleri detaylı olarak sunulmalıdır.

In vitro çalışmalar genellikle test ve referans ürün arasındaki farklılıkları belirlemede in vivo çalışmalardan daha spesifik ve duyarlıdır. $\mathrm{Bu}$ nedenle de preklinik çalışmaların temelini oluştururlar. Biyobenzerliği gösterebilmek için yapılan in vitro farmakodinamik çalışmalar arasında, reseptöre bağlanma çalışmaları, nötürleştirme denemeleri, hücre proliferasyonu denemeleri ve sitotoksisite çalışmaları gibi çalışmalar bulunmaktadır. In vivo farmakodinamik çalışmalar ise test edilmesi gereken biyolojik 
aktiviteyi yansıtan in vitro metodlar yok ya da yetersizse yapılabilir. Ancak kalite açısından önemli olabilecek bir fark olması durumunda (post-translasyonel modifikasyonlar, formülasyon farklııkları), in vivo çalışmaların gerekliliğine kanaat getirilirse, uygun tür, model, çalışma süresi, tasarım, 3R ilkeleri gibi noktalara özen gösterilmelidir. Bunların yanında yapılacak olan toksisite çalışmalarında amaç test ve referans ürünün potansiyel toksisitelerinin karşılaştırılmasıdır. Bu amaçla uygun deney hayvanı/modeli kullanılarak ürünün özellikleri (ürünün sınıfı, farmakokinetiği, klinik kullanımı vb.) dikkate alınarak çalışmalar gerçekleştirilir. Lokal tolerans gerekirse tekrarlayan doz toksisite çalışmaları içerisinde yapılır.

İmmünojenisite, biyobenzerler açısından oldukça önemli bir konu olup her ürün için ayrıca değerlendirilmelidir. İmmünojenisitenin etkisi sadece güvenlilik açısından değil, farmakokinetik/farmakodinamik farklılıkları yorumlamak için de önemlidir.

Preklinik testlerin ardından biyobenzerliğin klinik çalışmalar ile ispatlanması aşaması gelmektedir. $\mathrm{Bu}$ amaçla test ve referans ürüne ait farmakokinetik profillerin benzerliğinin değerlendirilebilmesi için faz-I çalışma yapılarak AUC, $C_{\text {trough, }} C_{\max }, t_{\max }$ gibi parametrelerin referans ürünle karşılaştırmalı olarak incelenmesi gerekir. Daha sonra etkililik ve güvenliliğin değerlendirileceği bir faz-III çalışma planlanmalıdır. Bu faz-III çalışma da referans ürünle karşılaştırmalı olarak yapıımalı ve molekül ve endikasyon dikkate alınarak uygun primer ve sekonder sonlanım noktaları seçilmelidir. Bu çalışmalarda ölçülebilecek farmakodinamik parametreler varsa onlar da değerlendirilmelidir. Molekülün birden fazla endikasyonu olması durumunda faz-III çalışmada endikasyon seçimini belirlerken en önemli nokta bu endikasyonlar için farklı etki mekanizmalarının kullanılıp kullanılmadığıdır. Eğer molekül tüm endikasyonlarda aynı etki mekanizması ile etkisini gösteriyorsa tek bir faz-III çalışma yeterlidir. Ancak farklı etki mekanizmaları etkiye aracılık ediyorsa ve biyobenzer ürün tüm endikasyonlar için ruhsat başvurusu yapacaksa faz-III çalışma her bir endikasyon için ayrı ayrı yapılmalıdır. Molekülün birden fazla aktif bölgesi olması ve bu bölgelerin öngörülen etkiler açısından önemli olup olmaması durumu da dikkate edilmesi gereken noktalardan biridir. $\mathrm{Bu}$ farklııılar biyoteknolojik bir ürün için sadece farklı hasta popülasyonlarında yapılan çalışmalarla ilgili olmayıp, farklı immünojenisite ve farklı toksisite anlamına da gelebilmektedir. $\mathrm{Bu}$ nedenle biyobenzer ürünlerin klinik çalışmaları ile ilgili değerlendirmeler yapılırken verilerin farklı endikasyonlar için ekstrapolasyonunda bu noktalara özellikle dikkat edilmelidir. Tüm çalışma süreci ve sonrasında farmakovijilans açısından da gerekli verilerin toplanarak bildirimlerin yapılması gerekir.

\section{Monoklonal Antikor Örneği}

Romatolojide sıklıkla kullanılan biyoteknolojik ürünlerin büyük kısmı monoklonal antikorlardır. $\mathrm{Bu}$ moleküllerin biyobenzerlerinin geliştirilme süreci molekülün büyük yapısı nedeni ile nispeten zordur. Monoklonal antikorların biyobenzerlerinin geliştirilmesinde tüm biyobenzerlerde olan detaylı fizikokimyasal karakterizasyonun ispatlanmasından sonra fonksiyon ile ilgili çalışmalar için ilk olarak in vitro aktivite çalışmaları yapılmalıdır. Bu çalışmalarda hedef antijene bağlanma, ilgili Fc-gamma reseptörler, FcRn ve komplemana bağlanma çalışmaları, Fab ile ilişkili fonksiyonlar (solübl ligandın nötralizasyonu, reseptör aktivasyonu veya blokajı), Fc ile ilişkili fonksiyonlar antikorbağımlı hücre-aracılı sitotoksisite (ADCC), kompleman-bağımlı sitotoksisite (CDC) gibi çalışmalar yapılmalıdır. Eğer mutlaka gerekli ise ve uygun modeller varsa in vivo aktivite için transgenik modeller, transplant modelleri kullanılabilir. Monoklonal antikorlar için uygun tür genellikle insan-dışı primatlardır (11).

Klinik faza geçildiğinde farmakokinetik parametrelerin benzerliğinin değerlendirilebilmesi için yapılacak çalışma tasarımında, molekülün kliniği, farmakokinetik özellikleri (hedef-aracılı dispozisyon, lineer/non-lineer farmakokinetik, yarılanma ömrü vb.) gibi faktörler göz önünde bulundurulur. $\mathrm{Bu}$ amaçla genellikle sağlıklı gönüllüler üzerinde tek doz paralel grup tasarım tercih edilir. Molekül sitotoksik bir etki mekanizmasına sahipse, farmakokinetik çalışma hasta gönüllülerde yapılmalıdır. Bu çalışma duruma göre monoterapi ya da kombinasyon tedavisi şeklinde yapılabilir (11). Örneğin romatolojide sıklıkla kullanılan TNF- $\alpha$ inhibitörü infliksimab biyobenzeri olan CT-P13'ün (Remsima) geliştirilme sürecinde faz-l farmakokinetik çalışmanın 250 ankilozan spondilit hastasında, faz-III çalışmanın ise 606 romatoid artrit hastasında yapıldığı görülmektedir (12-15). 
Bir etanersept biyobenzeri olan SB4 (Benapali)'ün ise faz-I farmakokinetik çalışması 136 sağlıklı gönüllüde yapılırken, faz-III çalışması 596 romatoid artrit hastasında yapılmıştır (16-17).

Klinik farmakodinamik-etkililik çalışması uygun hasta popülasyonunda yapılırken burada farmakodinamik belirteçlerin varlığı da değerlendirilmelidir. Daha sonra klinik sonlanım noktaları (örneğin kanser ilaçları için "Progressive free survival (PFS)", "overall survival (OS)" vb.'e ek olarak "Overall Response Rate (ORR)", "Complete Response (CR)" ya da "Partial Response (PR)" gibi parametreler) belirlenir.

Faz-III çalışmada güvenlilik parametreleri de incelenmelidir. Burada ilaca bağlı olabilecek tüm muhtemel yan etkiler (ör: ilaca bağlı kardiyotoksisite $\mathrm{vb}$ ) rapor edilmelidir. İmmünojenisite özellikle üzerinde durulması gereken noktalardan biridir. Molekülün boyutu ve yapının kompleks olması immünojenisiteyi daha da önemli bir hale getirmektedir. Bu nedenle çalışmalarda immünsupresan kullanmayan hastalar tercih edilmelidir. İmmünojenisite hastaya, hastalığa, ürüne ait faktörlere göre değişebilir. Farklı endikasyonlarda biyobenzerlerin immünojenisitesi de farklı olabilir. Örneğin rituksimaba karşı antikor oluşumu, Bhücreli malignitelerde daha nadirken, otoimmün hastalıklarda daha sık görülebilir. Bu antikorlar terapötik monoklonal antikorun antijen bağlama bölgesine karşı gelişerek ilacın etkinliğini inhibe edebilir. Dolayısıyla ilacın hem farmakodinamiğini, hem toksisitesini hem de farmakokinetiğini etkileyebilir (11).

\section{Sonuç}

Biyobenzerler ile ilgili yasal düzenlemeler tüm dünyada aktif ve gelişmekte olan bir süreçtir. Uzun süredir konu üzerinde yapılan çalışmalar, kazanılan tecrübeler ve hayvan modellerindeki gelişmeler nedeniyle düzenleyici otoritelerin biyobenzer kılavuzlarında zaman içerisinde değişiklikler olabilmektedir. $\mathrm{Bu}$ nedenle çalışmaların planlanması sırasında güncel literatürün EMEA, FDA ve TiTCK'nın konu ile ilgili kılavuzlarının takip edilmesi, mevcut ürünlerin EPAR, FDA, EMEA değerlendirme raporlarının gözden geçirilmesi önemlidir.

Bir diğer önemli konu da biyobenzerlerin değiştirilebilirlik ve ikamesidir. Bu konu uzun süredir tüm dünyada tartışımakta olup farklı otoritelerin farklı yaklaşımları mevcuttur. Bir biyolojik üründen diğerine geçmek antikor üretim riskini arttırmaktadır. Bu nedenle biyobenzer ilaçlar, referans ürün ile karşılaştırıldığında hasta immün sisteminden ve hastalıktan kaynaklanan özelliklerden daha farklı etkilenebilir. Bunun tersi de geçerlidir. $\mathrm{Bu}$ anlamda devam eden bir tedavide değişiklik yerine yeni ürünün yeni endikasyonda ya da yeni hastada kullanımasının daha doğru olacağı genel bir kanıdır. $A B$, biyoteknolojik ilaçların hekimin onayı ile değiştirilebilir olabileceğine, hekimin insiyatifi dışında yapılamayacağına karar vermiştir. Değiştirilebilirlik ve ikame ile ilgili mevcut veriler derinleştikçe bu konu ile ilgili uygulamalarda da değişiklikler olabilir. Ancak bunun için ulusal ve uluslararası veri tabanının (advers etki, güvenlilik vb) genişlemesi ve gerçek-yaşam verileri dikkate alınmalıdır. Bunun sağlanabilmesi için de biyobenzerlerin farmakovijilans ve izlenebilirliğinin geliştirilmesi gereklidir.

\section{Kaynaklar}

1. EMEA/CHMP/BMWP/42832/2005 Rev.1. Committee for Medicinal Products for Human Use (CHMP) Guideline on similar biological medicinal products containing biotechnology-derived proteins as active substance: non-clinical and clinical issues. 18 December 2014.

2. Development of Therapeutic Protein Biosimilars: Comparative Analytical Assessment and Other QualityRelated Considerations. Guidance for Industry. https://www.fda.gov/vaccines-blood-biologics/guidancecompliance-regulatory-information-biologics/biologics-guidances. May 2019, Biosimilars.

3. https://www.genengnews.com/a-lists/top-15-best-selling-drugs-of-2018/

4. https://www.statista.com/statistics/299138/top-selling-biotech-drugs-based-on-revenue/

5. EMEA/CHMP/BMWP/118264/2007 Rev.1. Committee for Medicinal products for Human (CHMP) Guideline on non-clinical and clinical development of similar biological medicinal products containing low-molecularweight-heparins. 10 November 2016. 
6. EMEA/CHMP/BMWP/32775/2005_Rev.1. Committee for Medicinal products for Human Use (CHMP). Guideline on non-clinical and clinical development of similar biological medicinal products containing recombinant human insulin and insulin analogues. 26 February 2015.

7. EMEA/CHMP/BMWP/301636/2008 Rev.1. Committee for Medicinal Products for Human Use (CHMP). Guideline on non-clinical and clinical development of similar biological medicinal products containing recombinant erythropoietins. 28 June 2018.

8. EMEA/CHMP/BMWP/31329/2005. Guidance on Similar Medicinal Products Containing Recombinant Granulocyte-Colony Stimulating Factor. London, 22 February 2006.

9. EMA/CHMP/BMWP/652000/2010. Committee for Medicinal Products for Human Use (CHMP) Guideline on similar biological medicinal products containing interferon beta. 21 February 2013.

10. EMEA/CHMP/BMWP/94528/2005 Rev.1. Committee for Medicinal Products for Human Use (CHMP) Annex to Guideline on similar biological medicinal products containing biotechnology-derived proteins as active substance: non-clinical and clinical issues. Guideline on similar medicinal products containing somatropin. 28 June 2018.

11. EMA/CHMP/BMWP/403543/2010. Committee for Medicinal Products for Human Use (CHMP). Guideline on similar biological medicinal products containing monoclonal antibodies - non-clinical and clinical issues. 30 May 2012.

12. Park W, Hrycaj $P$, Jeka $S$ et al. A randomised, doubleblind, multicentre, parallel-group, prospective study comparing the pharmacokinetics, safety, and efficacy of CT-P13 and innovator infliximab in patients with ankylosing spondylitis: the PLANETAS study. Ann Rheum Dis 2013; 72: 1605-12.

13. Yoo DH, Hrycaj $P$, Miranda $P$ et al. A randomised, double-blind, parallel-group study to demonstrate equivalence in efficacy and safety of CT-P13 compared with innovator infliximab when coadministered with methotrexate in patients with active rheumatoid arthritis: the PLANETRA study. Ann Rheum Dis 2013; 72: 1613-20.

14. Takeuchi T, Yamanaka H, Tanaka $Y$ et al. Evaluation of the pharmacokinetic equivalence and 54-week efficacy and safety of CT-P13 and innovator infliximab in Japanese patients with rheumatoid arthritis. Mod Rheumatol 2015; 25: 817-24.

15. Yoo DH, Racewicz A, Brzezicki J et al. A Phase III randomized study to evaluate the efficacy and safety of CTP13 compared with reference infliximab in patients with active rheumatoid arthritis: 54 -week results from the PLANETRA study. Arthritis Res Ther 2016;18:82.

16. Lee YJ, Shin D, Kim Y et al. A randomised Phase I pharmacokinetic study comparing SB4 and etanercept reference product (Enbrel®) in healthy subjects. Br J Pharmacol 2016; 82: 64-73.

17. Emery P, Vencovsky' J, Sylwestrzak A et al. A phase III randomised, double-blind, parallel-group study comparing SB4 with etanercept reference product in patients with active rheumatoid arthritis despite methotrexate therapy. Ann Rheum Dis 2017; 76: 51-7. 